\title{
NOVOS TÁXONS E NOTAS SOBRE CERAMBYCIDAE (COLEOPTERA) NEOTROPICAIS
}

\author{
Maria Helena M. Galileo ${ }^{1}$ \\ Ubirajara R. Martins ${ }^{2}$
}

\begin{abstract}
NEW TAXA AND NOTES ON NEOTROPICAL CERAMBYCIDAE (COLEOPTERA). New taxa described, Cerambycinae: Ibidionini, Cecaibidion gen. nov., type species, C. bivittatus sp. nov. from Panama; Acangassuini trib. nov., Acangassu gen. nov., type species, A. diminuta sp. nov. from Brazil (Rio de Janeiro); Necydalopsini: Eucharassus flavotibiale sp. nov. from Colombia (Valle) and E. confusus sp. nov. from Venezuela (Distrito Federal). Lamiinae: Onciderini, Iaquira gen. nov., type species, I. viridis sp. nov. from Brazil (Espírito Santo); Phacellini, Phacellus plurimaculatus sp. nov. from Brazil (Amazonas). Notes on Phacellus fulguratus Monné, 1979 and a key to the species of Eucharassus are added.
\end{abstract}

KEYWORDS. Acangassuini, Ibidionini, Necydalopsini, Onciderini, Phacellini.

\section{INTRODUÇÃO}

Novos táxons são descritos nas tribos Ibidionini, Acangassuini, trib. nov., e Necydalopsini (Cerambycinae) e em Onciderini e Phacellini (Lamiinae).

A tribo Ibidionini foi monografada por MARTINS (1967-1971, 1971) e novos táxons foram acrescentados para a fauna sul-americana (NAPP \& MARTINS, 1985a, b; MARTINS \& NAPP, 1986a, b; MARTINS \& GALILEO, 1999a) e para a fauna centro-americana (GIESBERT, 1998). Joly $(1990,1991)$ estudou as espécies ocorrentes na Venezuela. A granulação ocular é grossa em todas as espécies tratadas nesses trabalhos, exceto nas de Kunaibidion Giesbert, 1998. Igualmente, nas espécies de Stenygra Audinet-Serville, 1834 transferidas para Ibidionini por MARTINS \& GALILEO (1999b). Estamos propondo mais um gênero com olhos finamente granulados.

1. Museu de Zoologia, Universidade de São Paulo, Caixa Postal 42594, São Paulo SP, 04299-970, Brasil. (Pesquisador do CNPq).

2. Museu de Ciências Naturais, Fundação Zoobotânica do Rio Grande do Sul, Caixa Postal 1188, Porto Alegre RS, 90001-970, Brasil. (Pesquisador do CNPq). 
Mais uma tribo, Acangassuini, de Cerambycinae, semelhante a Ibidionini e Obriini é estabelecida para uma espécie nova do Rio de Janeiro, Brasil.

O gênero Eucharassus, da tribo Necydalopsini, foi estabelecido por BATEs (1885) para única espécie, E. dispar Bates, 1885, com acentuado dimorfismo sexual e proveniente do Panamá. Aurivillius (1891) incorporou ao gênero uma segunda espécie, E. nisseri, baseada numa fêmea da Colômbia. Melzer (1934) descreveu mais duas espécies fundamentadas em fêmeas: E. nevermanni e E. bicolor, ambas da Costa Rica. Acrescentamos ao gênero mais duas espécies; uma da Colômbia, E. flavotibiale, com fundamento num macho e uma da Venezuela, E. confusus, baseada numa fêmea. Apresentamos uma chave para distinguir as espécies de Eucharassus.

Na subfamília Lamiinae, descrevemos o gênero Iaquira na tribo Onciderini. Esta tribo foi revista por Dillon \& Dillon $(1945,1946)$ e muitos outros táxons foram acrescidos (Martins, 1979, 1981; Marinoni \& Martins, 1982; Monné \& Fragoso, 1984; Giesbert, 1984; Martins \& Galileo, 1990; Noguera, 1993).

Uma sinopse da tribo Phacellini foi apresentada por MonNÉ (1979) com chave para as seis espécies do gênero Phacellus Dejean, 1835. Adicionamos ao gênero mais uma nova espécie, $P$. plurimaculatus, e apresentamos notas sobre $P$. fulguratus Monné, 1979.

As siglas mencionadas no texto correspondem às seguintes coleções: CJEW, Coleção J. E. Wappes, West Des Moines; CMNH, Carnegie Museum of Natural History, Pittsburgh; CMNO, Canadian Museum of Nature, Ottawa; DZUP, Departamento de Zoologia, Universidade Federal do Paraná, Curitiba; INPA, Instituto Nacional de Pesquisas da Amazônia, Manaus; MCNZ, Museu de Ciências Naturais, Fundação Zoobotânica do Rio Grande do Sul, Porto Alegre; MZSP, Museu de Zoologia, Universidade de São Paulo, São Paulo.

\section{Cerambycinae \\ Ibidionini (V $\mathrm{V}^{\mathrm{a}}$ Divisão) \\ Cecaibidion gen. nov.}

Espécie-tipo, Cecaibidion bivittatum, sp. nov.

Etimologia. Tupi, cêcá = olho + Ibidion, gênero-tipo da tribo; alusivo aos olhos finamente granulados.

Fronte sem pubescência; fóveas laterais rasas, distantes dos olhos. Vértice sem pubescência, microesculturado. Tubérculos anteníferos projetados e distantes. Olhos finamente granulados. Distância entre os lobos oculares superiores cerca de seis vezes a largura de um lobo; lobos oculares inferiores com quase a metade do comprimento da área malar.

Antenas (macho) aproximadamente com o mesmo comprimento do corpo. Escapo subcilíndrico, sem sulco basal. Antenômeros III a VI engrossados; carenados na metade basal da face dorsal e com extremidade externa provida de espículo. Comprimento do III subigual ao de IV+V; o VI mais delgado que o V; comprimento do VI subigual ao do $\mathrm{V}$. Antenômeros VII a X com comprimentos gradualmente decrescentes. Antenômero XI pouco mais longo do que o precedente.

Protórax mais longo do que largo, com as constrições anterior e basal de igual largura. Pronoto com dois tubérculos anteriores e um central, todos arredondados no topo. Lados do protórax com faixa de pubescência serícea da base ao meio. Superfície 
do protórax muito lisa, brilhante e com algumas setas eretas. Cavidades coxais anteriores fechadas atrás.

Élitros com longas setas organizadas em três fileiras dorsais. Extremidades truncadas e desarmadas. Fêmures fortemente engrossados, pedunculados na base e adelgaçados para o ápice. Metatíbias carenadas no lado externo. Urosternito V com área centro-apical elevada em forma de "V".

Discussão. Nessa tribo, até MARTINs (1967-1971) e demais trabalhos posteriores, todas as espécies apresentavam olhos grosseiramente granulados. Recentemente, foram introduzidas, na tribo Ibidionini, espécies com olhos finamente granulados (GIESBERT 1998; Martins \& Galileo, 1999b)

GIESBERT (1998) ao descrever o gênero Kunaibidion não o alocou em nenhuma das divisões da tribo Ibidionini propostas por MARTINs (1967-1971). As cavidades coxais de Kunaibidion panamensis Giesbert, 1998 são fechadas ou diminutamente abertas atrás, os lobos oculares superiores são estreitos e os flagelômeros basais são lineares, sulcados e discretamente carenados (GIESBERT, 1998: 51). Esta combinação de caracteres situa Kunaibidion na V ${ }^{\mathrm{a}}$ Divisão. Recentemente, MARTINS \& GALILEO (1999b) incorporaram Stenygra A.-Serville, 1834, igualmente com olhos finamente granulados, transferindoo de Platyarthrini para a primeira divisão de Ibidionini.

$\mathrm{O}$ gênero Cecaibidion, que ora propomos, pertence à $\mathrm{V}^{\mathrm{a}}$ divisão pelas cavidades coxais anteriores fechadas atrás, flagelômeros basais engrossados nos machos e antenômero IV mais curto do que o III e do que o V. Além dos olhos finamente granulados, Cecaibidion gen. nov., separa-se de todos os gêneros da $\mathrm{V}^{\mathrm{a}}$ Divisão com flagelômeros basais engrossados pelas antenas com onze artículos, antenômeros III a VI carenados na metade basal e com espículo no lado externo do ápice e extremidades dos élitros transversalmente truncadas.

\section{Cecaibidion bivittatum sp. nov.}

(Fig. 1)

Macho (fig. 1). Colorido geral alaranjado. Fronte e vértice finamente microesculturados. Escapo com alguns pontos rasos e dispersos. Élitros com duas faixas de tegumento esbranquiçado: uma no meio da metade anterior, levemente oblíqua em sentido descendente da sutura para a margem sem atingir a sutura; outra, depois do meio, mais transversal, da margem até próximo da sutura. Lados do mesosterno e mesepimeros revestidos por pubescência serícea. Metasterno com mancha látero-posterior de pubescência serícea.

Dimensões em mm, ơ. Comprimento total, 7,7; protórax, comprimento 2,0, maior largura, 1,3; comprimento do élitro, 4,8; largura umeral, 1,7.

Material-tipo. Holótipo ớ, PANAMÁ, Panamá: El Llano (13-18 km N), 25.V-3.VI. 1983, J. E. Wappes col. (CJEW).

\section{Acangassuini trib. nov.}

Cabeça muito larga, notavelmente mais larga do que o protórax. Olhos emarginados, grosseiramente facetados, sem pêlos entre os omatídios, muito desenvolvidos, ocupam todo 


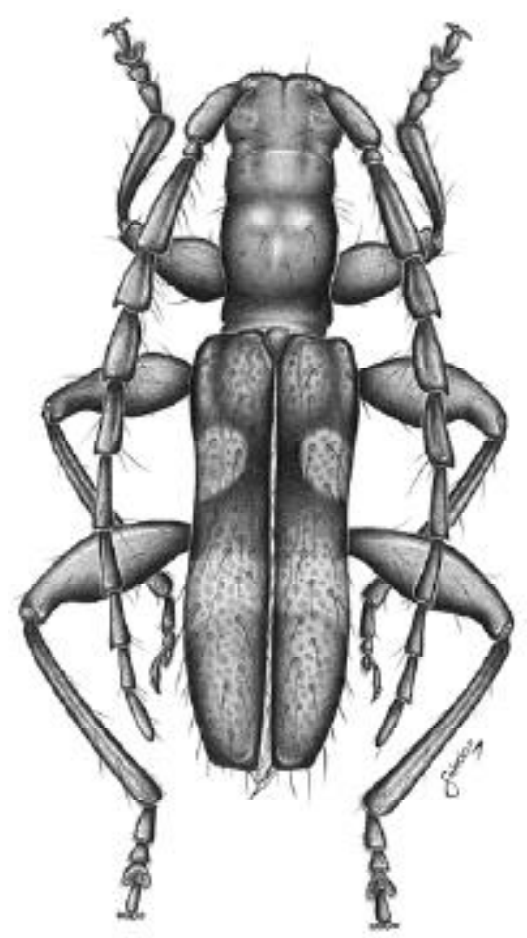

Fig. 1. Cecaibidion bivittatum sp. nov., holótipo ơ", comprimento 7,7 mm.

lado da cabeça. Palpos maxilares pouco mais longos do que os labiais; último artículo fusiforme.

Antenas com 12 artículos. Escapo cilíndrico, ligeiramente curvo e sem sulco no lado dorsal da base. Flagelômeros sem carenas. Antenômero III apenas mais curto do que o IV.

Protórax cilíndrico, mais longo do que largo e com lados subparalelos munidos de espinho fino e curto, situado pouco atrás de meio. Cavidades coxais anteriores nãoangulosas nos lados e fechadas atrás. Procoxas moderadamente salientes. Processo mesosternal com superfícies articulares laterais. Cavidades coxais intermediárias fechadas lateralmente. Fêmures sublineares, desarmados nos ápices. Tíbias não carenadas. Tarsos normais. Urosternito I tão longo quanto o II e com carena pós-coxal.

Discussão. Acangassuini assemelha-se a Ibidionini e Obriini. $\mathrm{O}$ aspecto geral é mais semelhante a Ibidionini, onde as espécies com protórax mais longo do que largo são a imensa maioria. Mas o protórax de Ibidionini é sempre desarmado aos lados, enquanto que o de Acangassuini apresenta um espículo lateral. Além disso, em Acangassuini a cabeça é muito larga com relação ao protórax e as antenas têm 12 artículos. Poucos gêneros de Ibidionini têm a cabeça tão larga e antenas com 12 artículos.

As espécies dos gêneros que compõem a tribo Obriini apresentam aspecto geral mais compacto e a cabeça pouco mais larga que o protórax ou de igual largura, as 
antenas têm onze artículos, o urosternito I é mais longo que o II+III nos machos e os fêmures são pedunculados e clavados. Em Acangassuini o aspecto geral é mais esbelto, a cabeça é acentuadamente mais larga que o protórax, as antenas têm 12 artículos, os urosternitos dos machos têm largura subigual e os fêmures são lineares.

\section{Acangassu gen. nov.}

Etimologia. Tupi, acanga = cabeça; açu = grande; alusivo à cabeça grande e larga. Espécie-tipo, Acangassu diminuta sp. nov.

Lobos oculares superiores com cinco fileiras de omatídios, com distância entre lobos menor que o diâmetro de um lobo. Lobos inferiores ocupam todo lado da cabeça. Genas muito curtas com borda arredondada. Antenômero III apenas mais curto que o IV; V-XI com comprimentos ligeiramente decrescentes; XII mais curto que o precedente. Processo prosternal muito estreito entre as procoxas. Processo mesosternal mais estreito que uma mesocoxa, sem tubérculo. Élitros desarmados no ápice. Urosternito I com carena pós-coxal. Urosternitos I-IV sem modificações ( $\left.\sigma^{\prime}\right)$ e indistintamente separados.

\section{Acangassu diminuta sp. nov.}

(Fig. 2)

Macho (fig. 2). Cabeça e protórax com tegumento avermelhado-escuro. Antenas e pernas amareladas. Élitros avermelhados gradualmente mais amarelados para os ápices; cada um com uma mancha amarelada, dorsal, que não toca a sutura, iniciada pouco atrás do úmeros e prolongada até o meio. Face ventral avermelhada. Cabeça, pronoto,

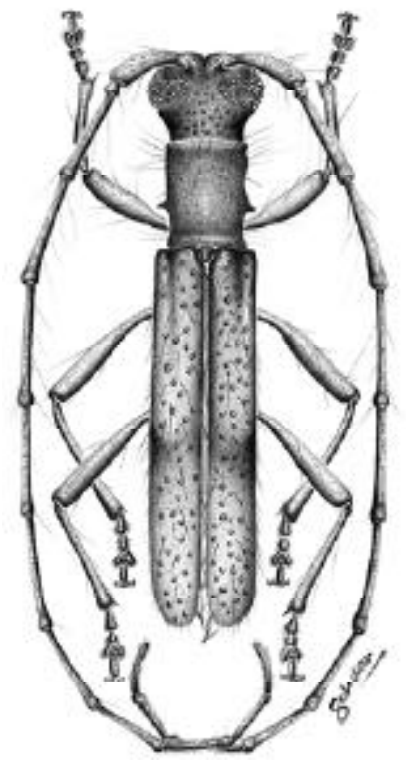

Fig. 2. Acangassu diminuta sp. nov., holótipo ở, comprimento 5,5 mm. 
pernas e face ventral com setas longas e esparsas. Pronoto recoberto por pubescência serícea mais adensada na metade basal. Élitros com pontuação grossa.

Dimensões em mm, on. Comprimento total, 5,5; maior largura da cabeça, 1,0; protórax, comprimento, 1,0, maior largura, 0,7; comprimento do élitro, 3,6; largura umeral, 1,0 . (DZUP).

Material-tipo. Holótipo ơ, BRASIL, Rio de Janeiro: Maricá (5 m), 10-15.I.1983, V. O. Becker col.

\section{Necydalopsini \\ Eucharassus Bates, 1885}

Eucharassus BAtes, 1885:308; MonNÉ, 1993:9 (cat.).

Chave para as espécies de Eucharassus.

1. Fêmures unicolores, pretos ..................................................................... 2

Fêmures bicolores, com a base amarelada e a metade apical preta ou castanha. 3

2(1). Fêmea: protórax, escutelo, mesepisterno e metasterno pretos ou castanhoavermelhados. Costa Rica ................................. nevermanni Melzer, 1934

Fêmea: protórax, escutelo, mesepisterno e metasterno avermelhados. (Protórax do macho com áreas anterior e posterior avermelhadas). Panamá....

E. dispar Bates, 1885

3(1). Pubescência elitral muito esparsa ou ausente; metatarsômeros pretos ............... 4

Pubescência elitral mais evidente no dorso; metatarsômeros amarelados .......... 5

4(3). Fêmea: antenas atingem o terço apical dos élitros; pronoto avermelhado, élitros pretos, unicolores. Costa Rica ................................ E. bicolor Melzer, 1934

Fêmea: antenas alcançam ou apenas ultrapassam o ápice elitral; pronoto preto; élitros bicolores, pretos e amarelos. Colômbia, Equador

E. nisseri Aurivillius, 1891

5(3). Macho: base dos flagelômeros III a VII, amarelados, sem pubescência serícea com a pilosidade restrita aos pêlos longos; pronoto sem tubérculos, com superfície regular e uma elevação discreta subtransversal no nível do terço anterior; habitus, fig. 3. Colômbia (Valle) .............................. E. flavotibiale sp. nov.

Fêmea: antenas unicolores, avermelhadas, com pubescência além dos pêlos longos; pronoto com dois tubérculos ao nível do meio e duas gibosidades no nível do terço basal; habitus, fig. 4. Venezuela (Distrito Federal) .E. confusus sp. nov.

\section{Eucharassus flavotibiale sp. nov.}

(Fig. 3)

Macho (fig. 3). Cabeça amarelo-avermelhada com áreas acobreadas na metade superior da fronte, nos tubérculos anteníferos e num anel na inserção com o protórax (menos na face ventral). Fronte e tubérculos anteníferos pontuados; região atrás dos tubérculos anteníferos finamente rugoso-pontuada. Antenas castanhas com a base dos antenômeros III-VII amarelada. Antenas ultrapassam o ápice elitral em 2-3 artículos; comprimento dos artículos V-X gradualmente decrescentes; X com aproximadamente a 


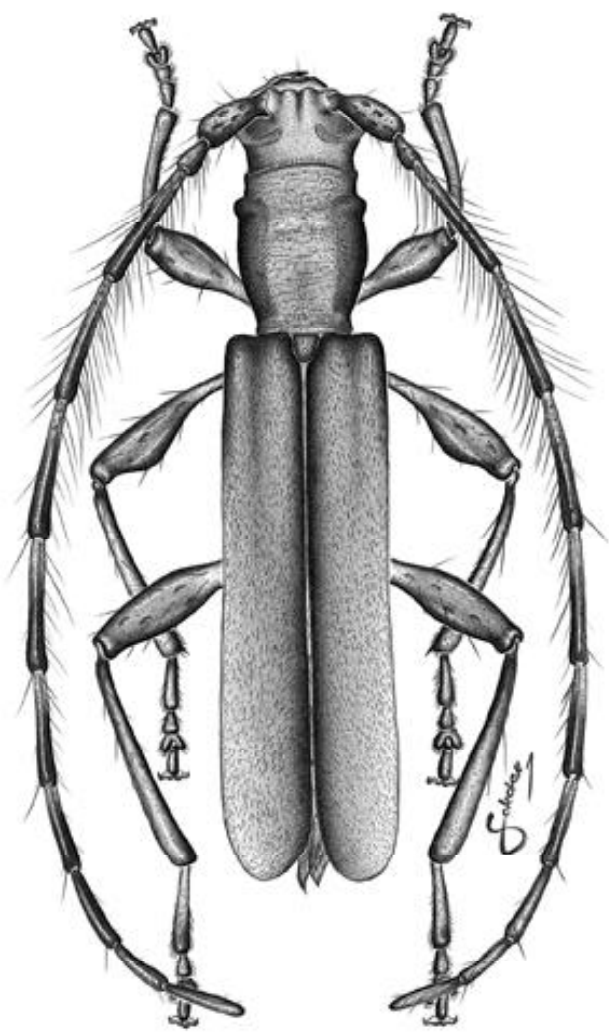

Fig. 3. Eucharassus flavotibiale sp. nov., holótipo ð’, comprimento 10,0 mm.

metade do comprimento do III; XI com comprimento subigual ao do IX. Escapo levemente engrossado para o ápice com pontos grandes; pedicelo com pontuação semelhante.

Protórax mais longo do que largo com a constrição basal mais acentuada do que a apical. Pronoto alaranjado com uma elevação transversal, curva, discreta, no nível do terço anterior, alcança os lados do protórax. Partes laterais do protórax arroxeadas, levemente elevadas, fina e muito densamente pontuadas e rugosas em sentido transversal. Prosterno liso no terço anterior com pontuação menos rugosa no restante da superfície. Processos prosternal e mesosternal laminiformes entre as coxas. Escutelo avermelhado. Esternos torácicos e urosternitos castanhos com brilho metálico. Élitros amarelados, translúcidos, finamente pubescentes. Fêmures com pedúnculo amarelado e clava castanha com reflexos metálicos. Tíbias e tarsos amarelados.

Dimensões em mm. Comprimento total, 10,0; protórax: comprimento 2,1, maior largura (no quarto anterior) 1,6, menor largura (na constrição basal) 1,1 ; comprimento dos élitros, 6,8; largura umeral, 2,0. Antenômero III, 1,6; antenômero V, 1,7; antenômero X, 0,8; antenômero XI, 1,0 .

Material-tipo. Holótipo ơ, COLÔMBIA, Valle: Pichinde (5.000 pés), 24.II.1970, H. Howden col. (CMNO). 
Discussão. E. flavotibiale difere do macho que atribuímos a E. nisseri (vide comentários) pelos flagelômeros basais com anel amarelado na base; pelas tíbias e tarsos amarelados; pelo comprimento reduzido dos antenômeros apicais e pelas menores dimensões.

Comentários. Identificamos, com dúvida, quatro exemplares que coincidem bastante com a descrição de E. nisseri Aurivillius, 1891 baseada numa fêmea procedente da Colômbia, colecionada por Nisser e sem mais detalhes de procedência. O único ponto discordante da descrição é o colorido dos élitros: "elytrorum dimidia fere parte basali aurea" (AuRIVILLIus, 1891:100). Numa das fêmeas examinadas, proveniente da Colômbia (Valle del Cauca: Cali, MZSP), os élitros são pretos na base e amarelo-ovo no terço apical, portanto, o inverso da descrição e da ilustração originais. Neste exemplar também se observa uma pequena mancha amarelada junto à base dos élitros e acreditamos que a coloração elitral possa estar sujeita a acentuada variabilidade. Na segunda fêmea, procedente do Equador (Pichincha, Santo Domingo de los Colorados, MZSP), os élitros são como na fêmea colombiana, mas a base não tem vestígio de mancha amarelada.Um dos machos, também do Equador, é da mesma procedência da fêmea e acreditamos que seja o seu sexo oposto; difere amplamente no colorido e no aspecto do protórax, como aliás ocorre $\operatorname{com} E$. dispar Bates, 1885, única espécie com ambos os sexos conhecidos (BATES, 1885:308, 309) e bastante diferentes em colorido. Fronte, centro do vértice, meio do protórax, escutelo e élitros inteiramente avermelhados; coxas e bases dos fêmures, amarelados. No outro macho, também do Equador (Carchi, CMNH), os élitros são inteiramente amarelados. Concluise, portanto, que E. nisseri é espécie extremamente variável.

\section{Eucharassus confusus sp. nov.}

(Fig. 4)

Fêmea (fig. 4). Cabeça avermelhada. Lobos oculares superiores mais distantes entre si do que o quádruplo da largura de um lobo. Tubérculos anteníferos gradualmente elevados para o ápice. Pubescência da cabeça branco-amarelada. Antenas avermelhadas; atingem o ápice dos élitros aproximadamente na ponta do antenômero XI. Escapo subcilíndrico, mais curto do que o antenômero III. Pedicelo com cerca da metade do comprimento do escapo. Antenômeros III e IV gradualmente engrossados para a extremidade, providos de pêlos curtos. Antenômeros V a XI com comprimentos gradualmente decrescentes.

Protórax avermelhado, com pubescência amarelada esparsa, apenas mais longo do que largo; constrição basal mais pronunciada do que a apical. Pronoto com quatro elevações: duas látero-anteriores, pouco à frente do meio, bem projetadas, com ápice rombo e duas gibosidades látero-basais ao nível do terço posterior. Élitros avermelhados na região umeral e amarelados para os ápices. Superfície muito finamente microesculturada revestida por pubescência curta. Esternos torácicos avermelhados. Urosternitos I a IV amarelados; urosternito V acastanhado. Fêmures brilhantes, amarelados no pedúnculo e acastanhados na clava. Pro- e mesotíbias castanhoamareladas. Metatíbias com o terço basal amarelado e, o restante, castanho-amarelado. Tarsômeros III a V ou todos os tarsômeros amarelados.

Dimensões, mm. Comprimento total, 9,6; protórax, comprimento 1,6; maior largura 1,5, largura na constrição basal 1,4; comprimento do élitro, 6,6; largura umeral, 


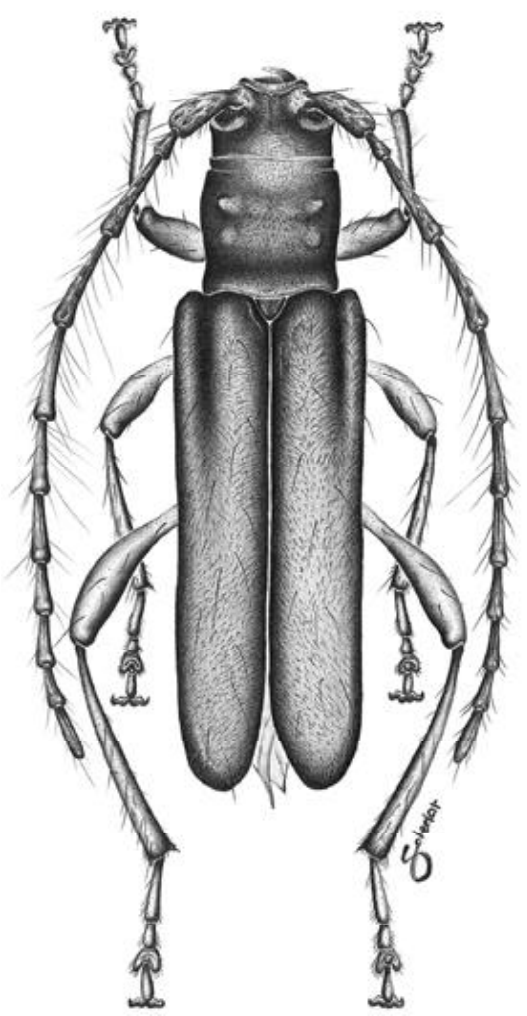

Fig. 4. Eucharassus confusus sp. nov., holótipo 9 , comprimento 9,6 mm.

2,3. Escapo, 1,0; pedicelo, 0,5; antenômero III, 1,3.

Material-tipo. Holótipo Y, VENEZUELA, Distrito Federal: Caracas (Cortada del Guayabo), 21.VII.1969, Bordon col. (enviado em permuta ao Dr. F. Lane em 1970, MZSP).

Discussão. A fêmea de E. confusus assemelha-se às fêmeas de E. nisseri e $E$. bicolor pelos fêmures amarelados na base e acastanhados ou pretos na clava. Distinguese de E. nisseri, pela coloração avermelhada da cabeça, antenas, protórax, fêmures e tarsos; pelos tubérculos pronunciados no pronoto; pelos élitros nitidamente aplanados na metade apical; pelo antenômero III sem sulcos ou carenas; pela face ventral avermelhada. Em E. nisseri o tegumento da cabeça, antenas, protórax e pernas é preto com reflexo metálico, verde ou violáceo; pronoto com tubérculos pouco elevados; élitros com epipleuras manifestas até o ápice; antenômero III preto com reflexos esverdeadometálicos e com sulcos e carenas. Difere da fêmea de E. bicolor, segundo a descrição original (Melzer, 1934), pela cabeça unicolor; pelos élitros avermelhados; pela presença de tubérculos evidentes no pronoto. Em E. bicolor a cabeça é bicolor, os élitros são pretos e o pronoto é irregular, sem tubérculos.

\section{Lamiinae}




\section{Onciderini \\ Iaquira, gen. nov.}

Espécie-tipo, Iaquira viridis sp. nov.

Etimologia. Tupi, iaquíra = verde; alusivo à pubescência esverdeada sobre o tegumento corporal.

Fronte mais longa do que larga. Olhos grosseiramente granulados. Lobos oculares superiores com quatro fileiras de omatídios, estreitados atrás da inserção das antenas. Lobos oculares inferiores apenas mais longos do que as genas. Tubérculos anteníferos distantes. Antenas ultrapassam a extremidade do corpo; nos machos, a partir aproximadamente do ápice do antenômero VI e, na fêmea, a partir da extremidade do VIII. Escapo fortemente clavado na metade apical; comprimento igual a 0,8 vezes o do antenômero III. Antenômero III levemente curvo no quarto basal. Antenômero XI, nos machos, mais longo do que o precedente, nas fêmeas, mais curto; antenômeros $\mathrm{V}$ a $\mathrm{X}$ com comprimentos subiguais.

Protórax mais largo do que longo e tão largo anteriormente quanto na base; lados desarmados, não escavados ou deprimidos ao nível do meio. Pronoto sem tubérculos ou gibosidades. Mesosterno sem tubérculo. Élitros com pontos simples, contrastantes com a pubescência; sem crista centro-basal, apenas com gibosidade arredondada no topo. Úmeros com tubérculo (mais projetado nos machos do que nas fêmeas), sem carena umeral. Metatíbias, nos machos, não engrossadas, desprovidas de sulcos ou áreas longitudinais escavadas.

Discussão. Pelo protórax tão largo anteriormente quanto na base e sem tubérculos laterais, pela fronte alongada, pelos élitros com pontuação simples, pelo antenômero III levemente arqueado na base, pelo escapo clavado e pelo pronoto sem rugas transversais assemelha-se a Proplerodia Martins \& Galileo, 1990 e Tibiosioma Martins \& Galileo, 1990. Difere de Proplerodia pelo antenômero III curvo na base; pelo escapo fortemente clavado, atinge o meio do pronoto; pelo processo prosternal sem elevação transversal; pelos úmeros com tubérculo e sem carena; pelas procoxas sem tubérculos unciformes; pelas metatíbias sem intumescimento e sem sulco. Em Proplerodia o antenômero III é reto; o escapo tem clava esbelta e quase alcança a borda posterior do pronoto; o processo prosternal apresenta elevação transversal pouco pronunciada; os úmeros não têm tubérculos e são prolongados em carena curta; as procoxas têm tubérculo unciforme e as metatíbias são intumescidas e têm um sulco estreito longitudinal. Difere de Tibiosioma pela fronte mais longa do que larga; pelo antenômero III sinuoso na base; pelas antenas dos machos nitidamente mais longas do que o corpo; pelos úmeros sem carenas e pelas meso- e metatíbias não dilatadas. Em Tibiosioma a fronte é quadrada; o antenômero III é reto; as antenas são apenas mais longas que o corpo nos machos; os úmeros prolongamse em uma carena curta e as meso- e metatíbias são acentuadamente dilatadas, com área de pubescência compacta.

\section{Iaquira viridis sp. nov.}

(Fig. 5)

Macho (fig.5)/fêmea. Tegumento, de maneira geral, preto a avermelhado. Pilosidade, em geral, esverdeada; no escutelo e no quinto basal dos élitros, mais 


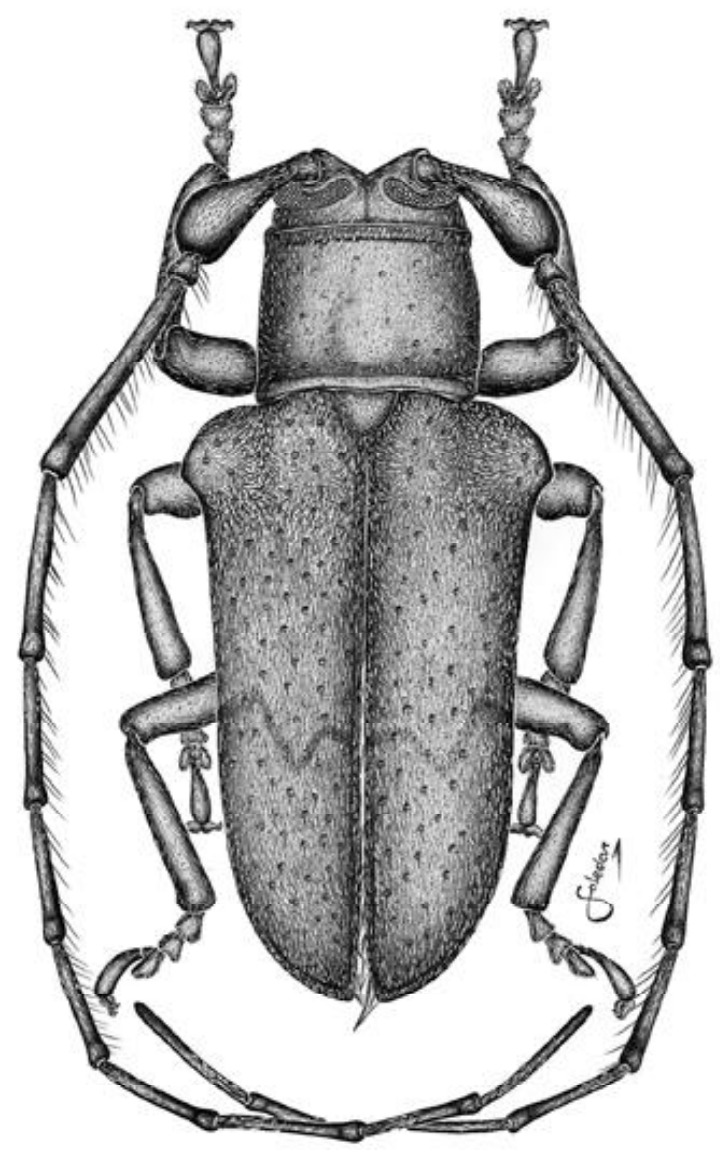

Fig. 5. Iaquira viridis sp. nov., holótipo ơ, comprimento 8,3 mm.

amarelada; nos lados do metasterno do macho, com leve reflexo metálico. Região central dos élitros com uma estreita faixa em "V" de pubescência mais escura

Fronte com alguns pontos entre os olhos. Escapo com clava revestida por esparsa pubescência castanha e a metade basal por pubescência esverdeada. Flagelômeros com a metade basal revestida por pubescência branco-amarelada ou esverdeada e a apical revestida por pubescência castanha. Pronoto muito esparsamente pontuado. Élitros com pontos grossos no quarto basal e gradualmente mais rasos em direção para o ápice; todos os pontos contrastantes com a pilosidade.

Dimensões, mm, ơ/9. Comprimento total, 8,3/9,3-11,0; protórax, comprimento 1,6/1,7-2,1, maior largura 2,2/2,3-3,0; comprimento do élitro, 5,8/6,9-8,0; largura umeral, 3,6/3,8-5,0; largura do élitro no meio, 3,2/4,2-4,4.

Material-tipo. Holótipo ơ BRASIL, Espírito Santo: Linhares, 24-31.VII.1972, C. Elias col. (DZUP); parátipo 9, 26-31.I.1976, C. Elias col. (MZSP); parátipo Y, São Mateus, III.1997, A. D. Brescovit col. (MCNZ).

\section{Phacellini}




\section{Phacellus fulguratus Monné, 1979}

Phacellus fulguratus MonNÉ, 1979:408, fig. 10; MonNÉ, 1994:25 (cat.).

Examinamos uma fêmea do Brasil, Santa Catarina, Timbó, V.1964, Dirings (MZSP) que atribuímos à espécie, mas difere da descrição original no que tange ao colorido. Neste exemplar, a pubescência branca é quase inaparente; o pronoto é unicolor e não apresenta máculas de pubescência branca junto aos ângulos posteriores; os élitros não tem faixa de pubescência branca no meio e não apresentam linha estreita, longitudinal, ao longo da sutura na metade apical. Neste espécime apenas as extremidades elitrais são estreitamente revestidas por pubescência branca e os élitros são unicolores.

\section{Phacellus plurimaculatus sp. nov.}

(Fig. 6)

Fêmea (fig.6). Tegumento castanho-escuro mais avermelhado nas antenas, pernas e face ventral. Pêlos na face dorsal do corpo e nos apêndices, longos, pretos e esparsos. Cabeça revestida por pubescência esbranquiçada, mais adensada no perímetro dos lobos inferiores dos olhos; pontuação fina e densa.

Antenas atingem os ápices elitrais aproximadamente na extremidade do artículo VIII com tufos de pêlos no lado interno dos antenômeros V e VI. Protórax com espinho lateral, manifesto, de ápice voltado para trás. Pronoto com linha central, longitudinal, muito estreita, de pubescência esbranquiçada e duas áreas grandes, laterais: uma dorsal ao espinho, nos lados da metade posterior; outra à frente do espinho junto à margem anterior. Superfície pronotal fina e uniformemente pontuada. Processo prosternal menos intumescido que o processo mesosternal; este com tubérculo muito desenvolvido. Escutelo revestido por densa pubescência esbranquiçada. Pubescência elitral com reflexos violáceocúpreos. Úmeros projetados com cerdas esparsas. Cada élitro com cinco manchas de pubescência esbranquiçada e compacta: uma subtransversal, dorsal, aproximada da sutura no quarto anterior; uma mediana, muito pequena, indistinta, perto da sutura; uma faixa lateral, transversal, ao nível do meio, que toca a margem e está distante da sutura; uma mancha próxima da sutura ao nível do quarto posterior e uma mancha apical que não toca as margens. Pontuação elitral mais grossa e mais esparsa do que a do pronoto, mais ou menos organizada em fileiras longitudinais na metade anterior e gradualmente menos evidente na metade apical. Pequena porção dos lados do metasterno e os metepisternos revestidos por pubescência branca, densa. Restante da face ventral com pubescência esbranquiçada mais esparsa.

Dimensões em mm, 9 . Comprimento total, 7,1; protórax, comprimento 1,4, maior largura 2,8; comprimento do élitro, 5,4; largura umeral, 2,8.

Material-tipo. Holótipo Y, BRASIL, Amazonas: Manaus (Reserva Ducke, 26 km N), 24.IX.1982, J. A. Rafael col., armadilha de Malaise (INPA).

Discussão. MonNÉ (1979) apresentou chave para distinguir as espécies do gênero Phacellus. P. plurimaculatus, pela presença de máculas de pubescência branca nos élitros e no pronoto, assemelha-se a $P$. dejeani Buquet, 1838 e $P$. fulguratus Monné, 1979. Distingue-se de $P$. dejeani pelo tufo de pêlos restrito ao lado interno dos antenômeros V 


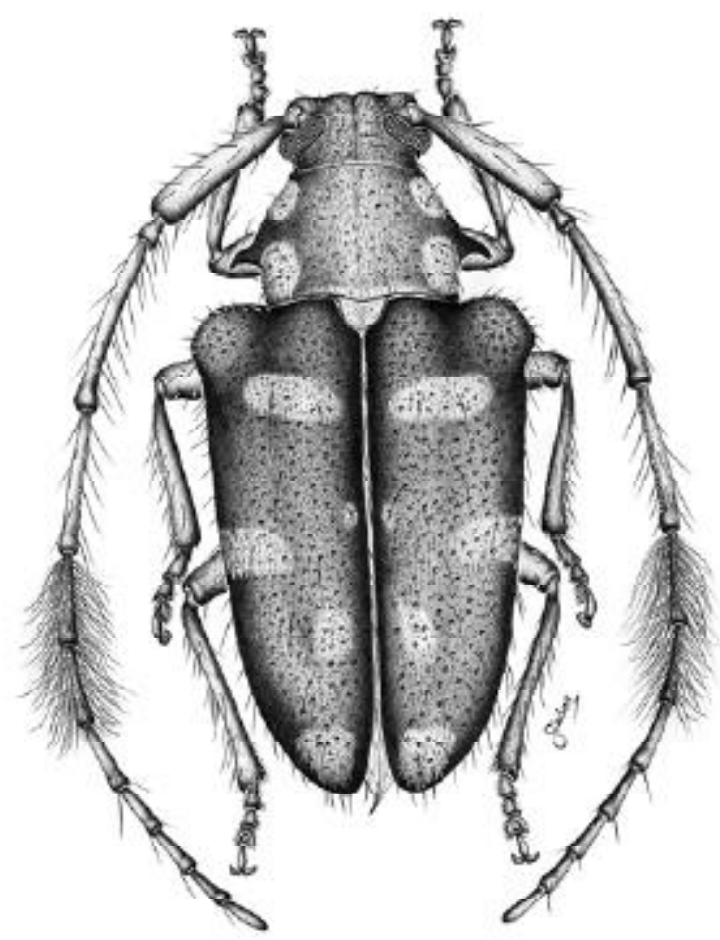

Fig. 6. Phacellus plurimaculatus sp. nov., holótipo 9 , comprimento 7,1 mm.

e VI, pela pubescência branca dos lados do pronoto organizada em duas grandes manchas laterais, pelo escutelo revestido por pubescência branca e pelo número maior de manchas de pubescência branca dos élitros. Em $P$. dejeani o tufo de pêlos nas antenas localiza-se no lado interno do ápice do antenômero IV e nos antenômeros V e VI; o escutelo não é revestido por pilosidade branca e, em cada élitro, contam-se apenas duas manchas de pubescência branca: uma transversal, no meio e uma apical. Difere de $P$. fulguratus pela presença de áreas brancas no pronoto; pelo escutelo e pelos metepisternos revestidos por pubescência branca e pelo maior número de áreas elitrais revestidas por pubescência branca. Em P. fulguratus o pronoto não tem áreas recobertas por pubescência branca; o escutelo e os metepisternos não apresentam pubescência branca e os élitros têm duas faixas de pubescência branca: uma transversal no meio e uma ao longo da sutura na metade apical.

Agradecimento. A Jorge Luis Dutra Soledar, bolsista de iniciação científica da FAPERGS pela arte final dos desenhos.

\section{REFERÊNCIAS BIBLIOGRÁFICAS}

Aurivillius, C. 1891. Neue Coleoptera Longicornia. Ent. Tidskr., Stockholm, 12: 97-107.

Bates, H. W. 1885. Biologia Centrali-Americana, Insecta, Coleoptera. Suplement to Longicornia. London,

British Museum of Natural History, v. 5, p. 249-436. 
Dillon, L. S. \& Dillon, E. S. 1945. The tribe Onciderini (Coleoptera, Cerambycidae). Part I. Scient. Publs Reading publ. Mus., Reading, 5: 1-186.

. 1946. The tribe Onciderini (Coleoptera, Cerambycidae). Part II. Scient. Publs Reading publ. Mus., Reading, 6: $189-413$.

GIESBERT, E. F. 1984. The genus Ischiocentra in Central America (Coleoptera, Cerambycidae). Wasmann J. Biol., San Francisco, 42: 78-83.

. 1998. New Ibidionini from Mexico and Central America (Coleoptera, Cerambycidae, Cerambycinae). Occ. Pap. Consortium Coleopterorum, Burbank, 2(1): 44-59.

JoLy, L. J. 1990. Los Ibidionini (Coleoptera: Cerambycidae) de la Expedición al Cerro de la Neblina. Revta Fac. Agron., Maracay, 16: 207-218.

_. 1991. Sinopsis de la tribu Ibidionini (Coleoptera, Cerambycidae) en Venezuela. Acta terramaris, Caracas, 4: 1-84.

Marinoni, R. C. \& Martins, U. R. 1982. Notas e descrições em Cacostola Fairm. \& Germ., 1859 (Onciderini, Lamiinae, Cerambycidae, Coleoptera). Revta bras. Ent., São Paulo, 26(3-4): 247-251.

Martins, U. R. 1967-1971. Monografia da tribo Ibidionini (Coeloptera, Cerambycidae), partes I-VI. Arq. Zool. Est. S. Paulo, São Paulo, 16(1-6): 1-1508.

—. 1971. Notas sobre Cerambycinae VI (Coleoptera, Cerambycidae). Subsídios ao conhecimento dos Ibidionini. Arq. Zool., São Paulo, 21(3): 121-178.

—. 1979. Descrições e notas sobre Onciderini (Coleoptera, Cerambycidae). Revta bras. Ent., São Paulo, 23(3): 147-156.

—. 1981. Descrições e notas sobre Onciderini II (Coleoptera, Cerambycidae). Papéis Avuls Zool., São Paulo, 34(20): 205-219.

Martins, U. R. \& Galileo, M. H. M. 1990. Onciderini (Coleoptera, Cerambycidae, Lamiinae): sinonímias, novos táxons, chaves e notas. Papéis Avuls Zool., São Paulo, 37(4): 53-95.

—. 1999a. Novas espécies de Ibidionini (Coleoptera, Cerambycidae) da América do Sul. Revta bras. Ent., São Paulo, 43(3-4): 301-307.

—. 1999b. Transferência de Stenygra A.-Serville, 1834 para Ibidionini (Coleoptera, Cerambycidae, e descrição de Isostenygra gen. nov. Revta bras. Ent., São Paulo, 43(3-4): 315-317.

MARTins, U. R. \& NAPP, D. S. 1986a. Ibidionini (Coleoptera, Cerambycidae). III ${ }^{a}$. Divisão: descrições, notas e chave para as espécies de Minibidion. Revta bras. Ent., São Paulo, 30: 5-12.

_. 1986b. Ibidionini (Coleoptera, Cerambycidae), Vª Divisão: descrições e notas. Revta bras. Ent., São Paulo, 30: $227-241$.

Melzer, J. 1934. Novos subsídios para o conhecimento dos cerambycideos neotrópicos. Revta Ent., Rio de Janeiro, 4(1): 70-110.

MonNÉ, M. A. 1979. Notas e descrições em Phacellini (Coleoptera, Cerambycidae, Lamiinae). Revta bras. Biol., Rio de Janeiro, 39(2): 405-413.

_. 1993. Catalogue of the Cerambycidae (Coleoptera) of the Western Hemisphere. Part X. São Paulo, Sociedade Brasileira de Entomologia. $79 \mathrm{p}$.

_. 1994. Catalogue of the Cerambycidae (Coleoptera) of the Western Hemisphere. Part XVI. São Paulo, Sociedade Brasileira de Entomologia. 98 p.

Monné, M. A. \& Fragoso, S. A. 1984. Notas sobre Onciderini (Coleoptera, Cerambycidae, Lamiinae). Pesq. Agropec. Bras., Brasília, 19(8): 925-933.

NAPP, D. S. \& MARTins, U. R. 1985a. Ibidionini (Coleoptera, Cerambycidae). I I Divisão: -notas, chaves e descrições. Papéis Avuls Zool., São Paulo, 36(12): 111-130.

—. 1985b. Ibidionini (Coleoptera, Cerambycidae). IV ${ }^{a}$ Divisão: descrições, sinonímias e chave para as espécies do gênero Cycnidolon. Papéis Avuls Zool., São Paulo, 36(13): 131-146.

Noguera, F. A. 1993. Revisión taxonómica del genero Oncideres Serville en Mexico (Coleoptera: Cerambycidae). Folia Entomol. Mex., Xalapa, 88: 9-60. 